\title{
Correlates of physical activity in young people: Anarrative review of reviews. Implications for physical education based on a socio-ecological approach \\ Correlatos de actividad física en jóvenes: Una revisión narrativa de revisiones. Implicaciones para la Educación Física basada en un enfoque socio-ecológico \\ *João Martins, *Adilson Marques, *Miguel Peralta, **António Palmeira, **Francisco Carreiro da Costa \\ *Universidade de Lisboa (Portugal), **Universidade Lusófona (Portugal)
}

\begin{abstract}
School and physical education (PE) play an important role in promoting youth physical activity (PA). Although there is extensive evidence about the correlates of PA in youth, few studies summarize these findings and critically connect them to PE based on a socio-ecological approach. The purpose of this article was to perform a narrative review of systematic reviews and of systematic reviews of reviews about the correlates of PA for children and adolescents, and to identify practical implications to PE using a socio-ecological model as a framework. Reviews were identified from searches in Pubmed, PsycINFO, Sportdiscus, ERIC, Web of science databases from 2000 through 2016. Based on established criteria, 20 reviews and four reviews of reviews were analysed. Results were presented in tables and through a narrative synthesis. The main correlates of PA for children and adolescents were: sex (male), age (inverse association), self-efficacy, previous PA, time spent outside (children), parental support, and access to facilities/programs of PA. The implications for PE were critically analyzed around five emerging themes: (1) active PE, (2) learning focused PE and PA for life, (3) Motivational climate in PE and students' psychosocial profiles, (4) Family and friends, and (5) comprehensive school PA promotion. Efforts to increase school and PE effectiveness by promoting active lifestyles require a comprehensive approach, and should be based on the design of $\mathrm{PE}$ and PA programs and the implementation of strategies that build on the main multilevel correlates of PA.
\end{abstract}

Keywords: School, physical education, physical activity, correlates, socio-ecological, revision, children, adolescents.

Resumen. La escuela y la educación física (EF) desempeñan un papel importante en la promoción de la actividad física (AF) en la juventud. Aunque existe una amplia evidencia acerca de los correlatos de la AF en los jóvenes, pocos estudios resumen estos hallazgos y los vinculan críticamente a la EF basándose en un enfoque socio-ecológico. El propósito de este artículo fue realizar una revisión narrativa de revisiones sistemáticas y de revisiones sistemáticas de revisiones sobre los correlatos de la AF para niños y adolescentes, e identificar implicaciones prácticas para la EF, usando como marco un modelo socio-ecológico. Las revisiones se identificaron a partir de búsquedas realizadas en las bases de satos de Pubmed, PsycINFO, Sportdiscus, ERIC, y Web of science, de 2000 a 2016. Sobre la base de criterios establecidos, se analizaron 20 revisiones y cuatro revisiones de revisiones. Los resultados fueron presentados en tablas y mediante una síntesis narrativa. Los principales correlatos de la AF para niños y adolescentes fueron: sexo (masculino), edad (asociación inversa), autoeficacia, AF previa, tiempo pasado fuera (niños), apoyo de los padres y acceso a instalaciones/programas de AF. Las implicaciones para la EF fueron analizadas críticamente alrededor de cinco temas emergentes: (1) educación física activa, (2) aprendizaje centrado en la EF y la AF para la vida, (3) clima motivacional en la EF y perfiles psicosociales de los estudiantes, (4) familia y amigos, y (5) la promoción integral de la AF escolar. Los esfuerzos para incrementar la efectividad de la escuela y de la EF en la promoción de estilos de vida activos, requieren un enfoque integral y deben basarse en el diseño de programas EF y AF y la implementación de estrategias basadas en los principales correlatos a varios niveles de AF.

Palabras clave: Escuela, educación física, actividad física, correlatos, socio-ecológico, revisión, niños, adolescentes.

\section{Introduction}

Promoting healthy and physically active lifestyles is a main goal for schools and physical education (PE) (UNESCO, 2015). However, because the majority of children and adolescents do not attain the recommended levels of physical activity (PA) to benefit their health (Hallal et al., 2012; Sallis et al., 2016; WHO, 2010), this becomes a major challenge. This situation is even more critical, when evidence shows that inactive adolescents tend to be inactive adults (Telama et al., 2014) and that many chronic diseases, like obesity and type II diabetes, start during youth (WHO, 2010).

In order to design more effective school and PE programs and strategies to promote physically active lifestyles, especially outside school and throughout life, it is important to know which are the main factors associated with PA behaviour (Mckenzie \& Lounsbery, 2013). These factors have been extensively studied (e.g. Bauman, Sallis, Wells, Loos \& Martin, 2012; Biddle, Cavill \& Foster, 2011; Sallis, Prochaska \& Taylor, 2000). According to the ecologic model (Sallis \& Owen, 2015), there are multiple levels of influence on PA, namely, individual (e.g. sex, motivation), social (e.g. friends support, family support) and environmental (e.g. equipment and PA programs in the community). Because multilevel interventions are considered to be more effective in changing behaviours (Sallis \& Owen, 2015), for promoting PA within and beyond PE and school contexts, a socio-ecological-approach is required.

Although there are several reviews (e.g. Sallis et al., 2000; Van der Horst, Chin, Twisk \& Van Mechelen, 2007) and reviews of reviews

Fecha recepción: 06-06-16. Fecha de aceptación: 15-11-16 Fecha recepcion:

jfigueiramartins@gmail.com (e.g. Bauman et al., 2012; Biddle et al., 2011) about the main correlates of PA, few studies summarize the findings and connect them to school and PE. Moreover, because factors at multiple levels can interact and influence PA, a socio-ecologic approach of PE can be a useful reference for understanding the many ways on how PE professionals can better promote children and adolescent PA levels, within and beyond school, and throughout life (Devís-Devís, Béltran Carrillo \& Peiró-Velert, 2015; Martins et al., 2016; O’Connor, Alfrey \& Payne, 2012; Solmon, 2015).

The present study had two main objectives: (1) to perform a comprehensive and narrative review of the systematic reviews or metaanalysis, and reviews of reviews about the correlates of PA for children and adolescents; and (2) to critically analyse the results of the narrative review and identify practical implications to PE based on a socioecological approach.

\section{Narrative review of reviews}

The present narrative review of reviews sought to summarize the literature findings regarding the factors associated with regular PA participation among children and adolescents. In a narrative review the selection of studies to use does not have to obey a systematic criteria (Granth \& Booth, 2009). However, to reduce bias and to select relevant studies for this topic, in august 2016 an exploratory search in five databases was performed (Pubmed, PsycINFO, Sportdiscus, ERIC, Web of science). The search terms used were as follows: «physical activity» OR «physical exercise» OR «health behaviour» AND «correlates» OR «determinants» OR «mediators» OR «associated factors» OR «psychosocial» OR «physical education» OR «environment» $A N D$ «childhood» $O R$ «adolescence» $O R$ «children» $\mathrm{OR}$ «adolescents» $\mathrm{AND}$ «review» $\mathrm{OR}$ «systematic review» $\mathrm{OR}$ «metaanalysis» OR «research synthesis». 
Table 1.

\begin{tabular}{|c|c|c|c|c|c|c|c|c|}
\hline \multirow{3}{*}{$\begin{array}{c}\begin{array}{c}\text { Review study } \\
\text { (first author and year } \\
\text { of publication) }\end{array} \\
\text { Sallis } 2000\end{array}$} & \multirow{2}{*}{ Years covered } & \multirow{2}{*}{$\begin{array}{c}\text { Sample } \\
\text { characteristics }\end{array}$} & \multirow{2}{*}{$\begin{array}{c}\text { Number and } \\
\text { design of studies } \\
\text { reviewed } \\
\text { (cross-sectional/ } \\
\text { prospective) }\end{array}$} & \multicolumn{5}{|c|}{ Correlates studied } \\
\hline & & & & $\begin{array}{l}\text { Demographic } \\
\text { and biological }\end{array}$ & sychological & Behavioural & Sociocultural $\mathrm{E}$ & Environmental \\
\hline & 1970-1998 & $\begin{array}{l}\text { Boys and girls } \\
\text { 3-18 years }\end{array}$ & $108(88 / 20)$ & $\mathrm{x}$ & $\mathrm{x}$ & $\mathrm{x}$ & $\mathrm{x}$ & $\mathrm{x}$ \\
\hline Biddle 2005 & 1999-2005 & $\begin{array}{l}\text { Girls } \\
10-18 \text { years }\end{array}$ & $51(41 / 10)$ & $\mathrm{x}$ & $\mathrm{x}$ & $\mathrm{x}$ & $\mathrm{x}$ & \\
\hline Davison 2006 & 1990-2006 & $\begin{array}{l}\text { Boys and girls } \\
3-18 \text { years }\end{array}$ & $33(30 / 3)$ & & & & & $\mathrm{x}$ \\
\hline Gustafson 2006 & Not described & $\begin{array}{l}\text { Boys and girls } \\
\text { 3-18 years }\end{array}$ & $34(30 / 4)$ & $\mathrm{x}$ & & & $\begin{array}{c}\mathrm{x} \\
\text { (Parents) }\end{array}$ & \\
\hline Ferreira 2006 & $1980-2004$ & $\begin{array}{l}\text { Boys and girls } \\
3-18 \text { years }\end{array}$ & $150(121 / 29)$ & $\mathrm{x}$ & & & $\mathrm{x}$ & $\mathrm{x}$ \\
\hline Hanson 2007 & $1970-2007$ & $\begin{array}{l}\text { Boys and girls } \\
10-21 \text { years }\end{array}$ & $34(28 / 6)$ & $\begin{array}{c}\mathrm{x} \\
(\mathrm{SES})\end{array}$ & & & & \\
\hline Van der Horst 2007 & $1999-01 / 2005$ & $\begin{array}{l}\text { Boys and girls } \\
4-18 \text { years }\end{array}$ & $57(51 / 6)$ & $\mathrm{x}$ & $\mathrm{x}$ & $\mathrm{x}$ & $\mathrm{x}$ & $\mathrm{x}$ \\
\hline Lubans 2008 & Not described & $\begin{array}{l}\text { Boys and girls } \\
\text { 5-18 years }\end{array}$ & $7(0 / 7)$ & & $\mathrm{x}$ & & $\mathrm{x}$ & \\
\hline Edwardson 2010 & Until 09/2009 & $\begin{array}{l}\text { Boys and girls } \\
6-18 \text { years }\end{array}$ & $96(85 / 11)$ & & & & $\begin{array}{c}\mathrm{x} \\
\text { (Parents) }\end{array}$ & \\
\hline Stalsberg 2010 & Until 07/2009 & $\begin{array}{l}\text { Boys and girls } \\
13-18 \text { years }\end{array}$ & $62(54 / 8)$ & $\begin{array}{c}\mathrm{x} \\
\text { (SES) }\end{array}$ & & & & \\
\hline Craggs 2011 & Until 11/2010 & $\begin{array}{l}\text { Boys and girls } \\
4-18 \text { years }\end{array}$ & $46(0 / 46)$ & $\mathrm{x}$ & $\mathrm{x}$ & $\mathrm{x}$ & $\mathrm{x}$ & $\mathrm{x}$ \\
\hline Uijtdewilligen 2011 & 2004-2010 & $\begin{array}{l}\text { Boys and girls } \\
4-18 \text { years }\end{array}$ & $30(0 / 30)$ & $\mathrm{x}$ & $\mathrm{x}$ & $\mathrm{x}$ & $\mathrm{x}$ & \\
\hline Dumith 2011 & 1998-2009 & $\begin{array}{l}\text { Boys and girls } \\
10-19 \text { years }\end{array}$ & $26(0 / 26)$ & $\begin{array}{c}x \\
\text { (Age) }\end{array}$ & & & & \\
\hline Ding 2011 & Until 12/2009 & $\begin{array}{l}\text { Boys and girls } \\
3-18 \text { years }\end{array}$ & $103(99 / 4)$ & & & & & $\mathrm{x}$ \\
\hline Lim 2012 & Until 10/2010 & $\begin{array}{l}\text { Boys and girls } \\
3-18 \text { years }\end{array}$ & $11(0 / 11)$ & & & & $\begin{array}{c}\mathrm{x} \\
\text { (Parents) }\end{array}$ & \\
\hline Sawka 2013 & Until 06/2012 & $\begin{array}{l}\text { Boys and girls } \\
6-18 \text { years }\end{array}$ & $13(9 / 4)$ & & & & $\begin{array}{c}x \\
\text { (Friends) }\end{array}$ & \\
\hline Maturo 2013 & Until 05/2012 & $\begin{array}{l}\text { Boys and girls } \\
3-18 \text { years }\end{array}$ & $106(80 / 26)$ & & & & $\begin{array}{c}\mathrm{x} \\
\text { (Friends) }\end{array}$ & \\
\hline Oliveira 2014 & $2007-01 / 2012$ & $\begin{array}{l}\text { Boys and girls } \\
3-12 \text { years }\end{array}$ & $28(24 / 4)$ & & & & & $\mathrm{x}$ \\
\hline Yаo 2015 & $1970-11 / 2014$ & $\begin{array}{l}\text { Boys and girls } \\
2-18 \text { years }\end{array}$ & $115(94 / 21)$ & & & & $\begin{array}{c}\mathrm{x} \\
\text { (Parents) }\end{array}$ & \\
\hline Laird 2016 & Until 01/2015 & $\begin{array}{l}\text { Girls } \\
10-19 \text { years }\end{array}$ & $84(68 / 16)$ & & & & $\begin{array}{c}\mathrm{x} \\
\text { (Friends and } \\
\text { parents) }\end{array}$ & \\
\hline
\end{tabular}

aims, study design and number, years covered, studied correlates, main correlates and the direction of the effect for children and adolescents, and main conclusions. Based on the classification suggested by Sallis et al. (2000), and used by most reviews and reviews of reviews, the correlates may not be significantly associated ( 0 ; when only 0 to $30 \%$ of the primary studies included in the review support the association), have an undetermined association (?; 34-59\%), have a positive association (+;60-100\%) and have a negative association (-;60-100\%). The results were organized in five main categories of correlates (demographic and biological, psychological, behavioural, sociocultural and environmental), presented in tables and through a narrative synthesis. All factors presented in the tables had to be identified in at least two reviews.

Characteristics of the reviews included in the narrative review

The main characteristics of the 20 reviewed studies included in this narrative review are showed in table 1 . The reviews were published between 2000 and 2016, but comprised primary studies published from 1970 to 2015. Samples were composed of boys and girls, with ages ranging from 2 to 21 years old, except for two reviews composed of girls (Biddle, Atkin, Cavill \&

Each study included in this narrativereview had to meet the following criteria: (1) be a systematic review or meta-analysis of quantitative studies (cross sectional, longitudinal or prospective design), or a systematic review of reviews; (2) aim to analyse factors associated with $P A$ and review quantitative associations between measured variables and PA; (3) published in English; (4) between 2000 and 2016; (5) include healthy (e.g. not obese) children (2 to 12 years old) and/or adolescents (13 to 18 years old) as participants (when age limits were different, mean would have been used in that gap or data was presented separately for this specific age group).

Two researchers examined the title and abstracts to identify potentially relevant studies for a narrative review. Discrepancies were resolved by consensus. The selection of the studies to include in this review was executed through the complete reading of the information, considering the utility criteria, information saturation, diversity of analysed correlates, and feasibility of the review. Most reviews included in this narrative review have also been included in the reviews of reviews, which provide some guarantees to the quality of the evidence. A quality evaluation of the reviews was not performed in this narrative review. Additionally, in order to obtain a more comprehensive view of the correlates, reviews of less explored correlates (i.e. socioeconomic status, parents, friends, and environment) were included. Even though the strict procedures adopted, we acknowledge that there may exist other reviews that were not included in the present narrative review.

The data analysis for each review and review of reviews was carried out independently by two authors, which met to resolve divergences. The authors collected information about authors, year,
Foster, 2005; Laird, Fawkner, Kelly, McNamee \& Niven, 2016). Most reviews included cross-sectional and prospective studies.

Several reviews were focused in specific correlates, as socioeconomic status (Hanson \& Chen, 2007; Stalsberg \& Pedersen, 2010), age (Dumith, Gigante, Domingues \& Kohl, 2011), parents (Edwardson \& Gorely, 2010; Gustafsson \& Rhodes, 2006; Lim \& Biddle, 2012; Yao \& Rhodes, 2015), friends (Maturo \& Cunningham, 2013; Sawka McCormack, Nettel-Aguirre, Hawe, \& Doyle-Baker, 2013) or environment (Davison \& Lawson, 2006; Ding, Sallis, Kerr, Lee \& Rosenberg, 2011; Oliveira, Moreira, Abreu, Mota \& Santos, 2014). The remaining reviews comprehend correlates from multiple levels (e.g. Sallis et al., 2000; Van der Horst et al., 2007). The present narrative review also included the analysis of four reviews of reviews, published between 2011 and 2014, and presented in table 2 .

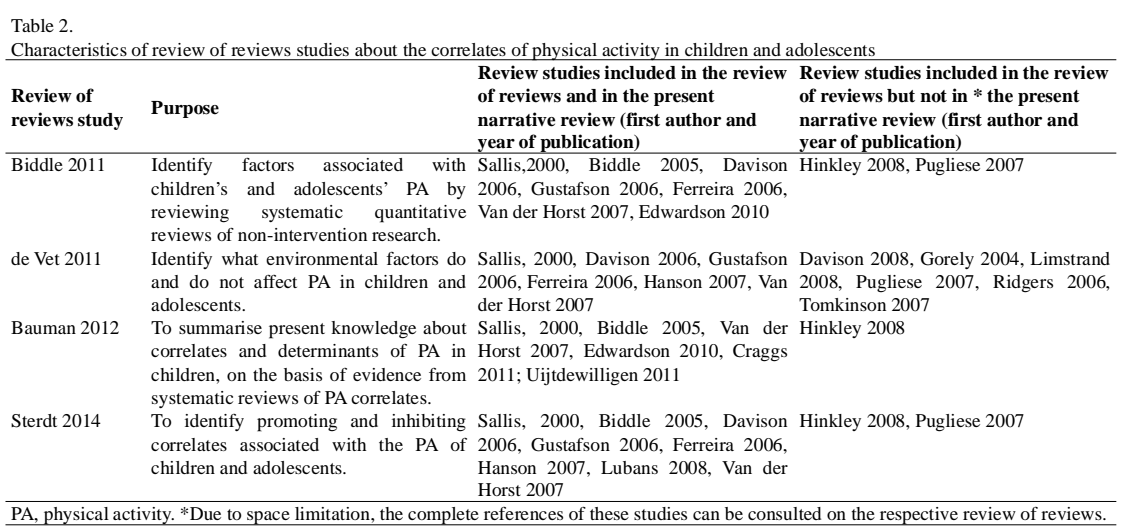

PA, physical activity. ${ }^{*}$ Due to space limitation, the complete references of these studies can be consulted on the respective review of reviews. 
2011; Sallis etal., 2000; Van der Horstetal., 2007) as well as in adolescence (Sallis et al., 2000; Van der Horst et al., 2007). The reviews of reviews corroborates that sex is one of the more consistent correlates of PA (Biddle et al., 2011; Bauman et al., 2012; Sterdt, Liersch \& Walter, 2014) (table 3).

Table 3.

Summary of demographic and biological correlates of physical activity of children and adolescents.

\begin{tabular}{|c|c|c|c|c|c|c|c|c|c|c|c|c|c|}
\hline Correlates & $\begin{array}{l}\text { Sallis } \\
2000\end{array}$ & $\begin{array}{l}\text { Biddle } \\
2005\end{array}$ & $\begin{array}{l}\text { Ferreira } \\
2006\end{array}$ & $\begin{array}{l}\text { Hanson } \\
2007\end{array}$ & Van der Horst & Stalsberg & Craggs & Uijtdewilligen 1 & Dumith & Lim & Biddle 1 & Bauman & $\begin{array}{c}\text { Sterdt } \\
2014\end{array}$ \\
\hline Sex (male) & $+/+$ & $1+$ & & & $+/+$ & & $\begin{array}{c}2011 \\
+/ ?\end{array}$ & $\begin{array}{l}\frac{2011}{? ? ?} \\
?\end{array}$ & & & $\frac{2011}{+/+}$ & $\frac{2012}{+/+}$ & $+/+$ \\
\hline Age & ?/- & 1- & & & $0 / ?$ & & $1-$ & $? /+$ & - & & 1- & & 1- \\
\hline Ethnicity (Caucasian) & ?/+ & 1+ & & & $0 / 0$ & & $? / 0$ & 1+ & & & ?/+ & ?/+ & 1+ \\
\hline BMI & ?/0 & 1- & & & $0 / 0$ & & & ?/? & & & & $0 / 0$ & \\
\hline SES & 10 & & $0 / 0$ & 1+ & $0 / 0$ & $1+$ & ?/? & & & + & ?/? & & 1+ \\
\hline SES (family income) & & 1+ & 1+ & & & & & & & & & & $1+$ \\
\hline Family education & & $1+$ & $0 / 0$ & & $0 /+$ & & & ?/? & & & & & $1+$ \\
\hline
\end{tabular}

al., 2007) and adolescents (Sallis et al., 2000; Uijtdewilligen et al., 2011) PA, as corroborated by Biddle et al. (2011). Three reviews and a review of reviews (Sterdt et al., 2014) also supported positive associations between attitude towards PA and PA participation in children or adolescents (Lubans, Foster \& Biddle, 2008; Sallis et al., 2000; Van der Hors et al., 2007). However, a review (Uijtdewilligen et al., 2011) and a review of reviews (Bauman et al., 2012) showed that this association is inconsistent or inexistent. Similar results were found regarding the perceived benefits of PAand enjoyment (Lubans et al., 2008; Sallis et al., 2000; Van der Horst et al., 2007) and attitude towards PE (Craggs et al., 2011; Lubans et al., 2008; Sallis et al., 2000).

For children, associations between age and PA are inconsistent (Sallis et al., 2000; Van der Horst et al., 2007; Uijtdewilligen et al., 2011). However, in adolescence, there is a decrease in PA participation, which is supported by reviews (Craggs et al., 2011; Dumith et al., 2011; Sallis et al., 2000) and reviews of reviews (Biddle et al., 2011; Sterdt et al., 2014). For example, Dumith et al. (2011) showed that from 10 to 19 years old, on average the mean percentage $\mathrm{PA}$ decline per year was $-7.0 \%$, and is greater among girls. Higher levels of previous PA (children), perceived behavioural control and support for PA (adolescents), as well as selfefficacy (children and adolescents) and were associated with smaller declines in PA(Craggs et al., 2011).

Results regarding the association between socioeconomic status and PAare not consensual. While some reviews (Sallis et al., 2000; Van der Horst et al., 2007) and reviews of reviews (Biddle et al., 2011) report no associations between socioeconomic status and PA for children and adolescents, others report positive associations (Biddle et al., 2005; Gustafson \& Rhodes, 2006; Lim \& Biddle, 2012; Sterdt et al., 2014). Divergentresults were also found when considering educational indicators (Ferreira et al., 2006; Van der Horst et al., 2007; Uijtdewilligen et al., 2011). Reviews dedicated to analyse associations between socioeconomic status and PA showed that high socioeconomic status adolescents tend to participate more in PA, but also that results were not uniform. For example, Stalsberg and Pedersen (2010) found that $42 \%$ of the 60 analysed studies reported a negative or an inexistent association between socioeconomic status and PA.

Reviews (Craggs et al., 2011; Sallis et al., 2000) and reviews of reviews (Bauman et al., 2012; Biddle et al., 2011) suggest that the associations between ethnicity and children PA are inconsistent. Still, some reviews (Biddle et al., 2005; Sallis etal., 2000; Uijtdewilligen etal., 2011) and reviews of reviews (Bauman et al., 2012; Biddle et al., 2011; Sterdt et al., 2014) suggest that adolescents from «Caucasian» ethnicity tend to be more physically active than their peers from other ethnicities.

Regarding the body mass index, a modifiable biological factor, reviews concluded that its association with PA in childhood and adolescence is inconsistent or inexistent (Bauman et al., 2012; Sallis et al., 2000; Van der Horst et al., 2007; Uijtdewilligen et al., 2011). Only Biddle et al. (2005) found a negative association between these two factors for adolescent girls.

\section{Psychological correlates of physical activity for children and adolescents}

A summary of the psychological correlates of PA is presented in table 4. The intention to practice PA was positively associated to children (Sallis et al., 2000; Uijtdewilligen et al., 2011; Van der Horst et

The perceived behavioural control (i.e. general self-perceptions about the capacity to be physically active) was inconsistently associated with PA in children (Craggs et al., 2011; Uijtdewilligen et al., 2011), but positively associated with PA in adolescents (Bauman et al., 2012; Craggs et al., 2011).

Although some reviews and a review of reviews showed an indeterminate association between perception of competence and PA in children (Bauman et al., 2012; Craggs et al., 2011; Sallis et al., 2000; Van der Horst et al., 2007) and adolescents (Van der Horst et al., 2011), several reviews found positive associations in adolescents (Biddle et al., 2005; Biddle et al., 2011; Sallis et al., 2000; Sterdt et al., 2014). None of the reviews presented findings about goal orientation in children. For adolescents, Sallis et al. (2000) and Van der Horst et al. (2007), found positive associations between goal orientation (mastery) and PA, which is corroborated by the studies of Biddle et al. (2011) and Sterdt et al. (2014). Lack of data and of consistency among these variables in children might occur because an effective perception of competence is only developed in late childhood (Biddle et al., 2011; Nicholls, 1989).

Accordingly to several reviews and reviews of reviews, self-efficacy (i.e. confidence in the ability to be physically active in specific situations) is one of the most consistent positive correlates of PA in children and adolescents (Bauman et al., 2012; Biddle et al., 2005; Craggs etal., 2011; Lubans et al., 2008; Sterdt et al., 2014; Van der Horst et al., 2007).

Excepting for Biddle's et al. (2005) review, who found that for adolescents girls having a better perception of body image was associated with $\mathrm{PA}$, the self-concept factors in general and body image perception were not associated with PA(Craggs et al., 2011; Sallis et al., 2000; Van der Horst et al., 2007).

Findings regarding associations among perceived barriers of PA (e.g. lack of time, money or interest; required effort to participate) and PA participation differ between studies. On the one hand, several reviews and reviews of reviews suggest that the perception of barriers of PA was consistently associated with lower participation in PA for children (Biddle et al., 2011; Sallis et al., 2000) and adolescents (Biddle et al., 2005; Biddle et al., 2011; Van der Horst et al., 2007, Sterdt et al., 2014). On the other hand, other reviews suggest that this association is inexistent or indeterminate (Bauman et al., 2012; Van der Horst et al., 2007). 


\section{Behavioural correlates of physical activity for children and adolescents}

As observed in table 5, for children (Craggs et al., 2011; Sallis et al., 2000) and adolescents (Sallis et al., 2000; Uijtdewilligen et al., 2011) previous participation in PA was identified as an important correlate of current participation in PA. Biddle et al. (2011) and Bauman et al. (2012) reviews of reviews corroborate the existence of a tracking of PA (tracking) in these age groups. Additionally, two reviews (Biddle et al., 2005; Sallis et al., 2000) and two reviews of reviews support that participating in organized PA in adolescence is associated with higher overall levels of PAand sustaining a physically active lifestyle (Biddle et al., 2011; Sterdt et al., 2014).

Table 5.

Summary of behavioural correlates of physical activity of children and adolescents.

\begin{tabular}{|c|c|c|c|c|c|c|c|c|}
\hline Correlates & $\begin{array}{l}\text { Sallis } \\
2000\end{array}$ & $\begin{array}{c}\text { Biddle } \\
2005\end{array}$ & $\begin{array}{c}\text { Van der Horst } \\
2007\end{array}$ & $\begin{array}{c}\text { Craggs } \\
2011\end{array}$ & $\begin{array}{c}\text { Uijtdewilligen } \\
2011\end{array}$ & $\begin{array}{c}\text { Biddle } \\
2011\end{array}$ & $\begin{array}{c}\text { Bauman } \\
2012\end{array}$ & $\begin{array}{c}\text { Sterdt } \\
2014 \\
\end{array}$ \\
\hline Previous physical activity & $+/+$ & & & $+/$ ? & ?/+ & $+/+$ & $+/+$ & \\
\hline Sport participation & $1+$ & $1+$ & & ? & & $1+$ & & 1+ \\
\hline Physical Education/School sports & 10 & & 1+ & & & & & \\
\hline Sedentary behaviour & $? / 0$ & /? & & ?/? & ?/? & ?/? & & \\
\hline Healthy diet & $+/ 0$ & & & /? & & & & \\
\hline Smoking & /? & /- & $/ 0$ & 10 & & 1- & $0 / 0$ & \\
\hline
\end{tabular}

+ positive association; - inverse association; 0 , no association; ? indeterminate association. A symbol placed in the left side of the "p" refers to children, on the right of the " $"$ " refers to adolescents. adolescents were related to their parents, friends and significant others (table 6). Parents' PA levels seem not to be associated with children (Craggs etal., 2011; Ferreira et al., 2006; Sallis et al., 2000; Uijtdewilligen et al., 2011) and adolescents (Craggs et al., 2011; Ferreira et al., 2006; Lubans, 2008; Sallis et al., 2000; Uijtdewilligen et al., 2011) participation in PA. This result is confirmed by Bauman's et al. (2012) review of reviews. However, when this association was observed, as in several reviews (Biddle et al., 2005; Edwardson \& Gorely, 2010; Gustafson \& Lawson, 2006; Laird et al., 2016; Van der Horst et al., 2017; Yao \& Rhodes, 2015) and Biddle's et al. (2011) review of reviews, it was weak and seemed to favor the association between children and adolescents PA levels and the father PA levels. When analysing the associations between the parents influence depending on the type and intensity of PA, Edwardson and Gorely (2010) found that the parents' PA levels were positively associated with children's and adolescents' moderate to vigorous PA and total PA. Sallis et al. (2000) review was the only one to verify a favourable association between adolescents' PA and their siblings' PA, while de Vet et al. (2011)

Table 6

Summary of sociocultural correlates of physical activity of children and adolescents.

\begin{tabular}{|c|c|c|c|c|c|c|c|c|c|c|c|c|c|c|c|c|c|}
\hline Correlates & $\begin{array}{l}\text { Sallis } \\
2000\end{array}$ & $\begin{array}{c}\text { Biddle } \\
2005\end{array}$ & $\begin{array}{c}\text { Gustafson } \\
2006\end{array}$ & $\begin{array}{l}\text { Ferreira } \\
2006\end{array}$ & $\begin{array}{l}\text { Van der Horst } \\
2007\end{array}$ & $\begin{array}{c}\text { Lubans } \\
2008\end{array}$ & $\begin{array}{c}\text { Edwardson } \\
2010\end{array}$ & $\begin{array}{c}\text { Craggs } \\
2011\end{array}$ & $\begin{array}{l}\operatorname{Lim} \\
2012\end{array}$ & $\begin{array}{c}\text { Sawka } \\
2013\end{array}$ & $\begin{array}{c}\text { Maturo } \\
2013\end{array}$ & $\begin{array}{r}\text { Yao } \\
2015 \\
\end{array}$ & $\begin{array}{l}\text { Laird } \\
2016\end{array}$ & $\begin{array}{c}\text { Biddle } \\
2011\end{array}$ & $\begin{array}{c}\text { de Vet } \\
2011\end{array}$ & $\begin{array}{c}\text { Bauman } \\
2012\end{array}$ & $\begin{array}{l}\text { Sterdt } \\
2014\end{array}$ \\
\hline Father PA & & 1+ & + & $+/ 0$ & +1 & & $+(\mathrm{LTPA}) /+$ & & & & & + & + & & & & \\
\hline Mother PA & & ? & + & $0 / 0$ & $0 /$ & & t/+ & & & & & & 0 & & & & \\
\hline Parental support & 1+ & 1+ & + & /? & t/t+ & & /+(MVPA,VPA,TPA) & ?/? & & & & + & + & t/t+ & 0 & t/t+ & t/t+ \\
\hline Parental encouragement & $0 /$ & & & $0 /$ ? & & & t/+ & & & & & + & + & & & & \\
\hline Transport & $0 /$ & & & $0 /$ ? & & & +/+(MVPA,LTPA) & & + & & & + & + & & & & \\
\hline Friends PA & 10 & & & $0 / 0$ & & 0 & & ?? & & + & + & & + & & 0 & & \\
\hline Friends support & /? & /? & & 10 & 1+ & + & & /? & & & + & & + & & & & \\
\hline PA co-participation - friends & & /? & & & & & & & & & + & & & & & & \\
\hline Significant others support & 1+ & & & $0 /+$ & & & & & & & & & + & & & & 1+ \\
\hline
\end{tabular}

The following results comprise the behavioural correlates associated with participation in PE or in school sports. These results potentially represent the factors that are modifiable through PE. Results showed that participation in $\mathrm{PE}$ or in school sports were associated with higher levels of PA for adolescents in Van der Horst et al. (2007) and Biddle et al. (2005) reviews, but not in Sallis et al. (2000) review. From the included studies in this narrative review, only few of them specifically analysed associations between PE or school sports and PA.

In their review Sallis et al. (2000) reported the existence of an inverse association between sedentary behaviour and PA in children, during weekend and hours after school. Other reviews concluded that sedentary behaviour (e.g. watch television) was not associated, or presented an inconsistent association, with children's and adolescents' PA (Biddle et al., 2005; Biddle et al., 2011; Craggs et al., 2011; Uijtdewilligen et al., 2011; Van der Horst et al., 2007).

Smoking may not be associated with PA (Bauman et al., 2012; Craggs et al., 2011; Sallis et al., 2000; Van der Horst et al., 2007), although some studies found a negative association in adolescent girls (Biddle et al., 2005; Biddle et al., 2011). Regarding eating habits, Sallis et al. (2000) found that for children having an healthy diet was positively associated with PA, but the same was not true for adolescents. Craggs etal.(2011) reported inconclusive findings about the association between these two variables.

Sociocultural correlates of physical activity for children and adolescents

The main sociocultural factors associated to PA in children and concluded that there was no association.

For children, Van de Horst et al. (2007) reported positive associations between parents support and children PA, while Craggs et al. (2011) verified inconclusive results. As for adolescents, although somereviews reported inconclusive findings (Craggs et al., 2011; Ferreira et al., 2006), most of them found a positive association between parents' support and adolescents PA (Biddle et al., 2005; Sallis et al., 2000; Van der Horst et al., 2007). Several reviews (Edwardson \& Gorely, 2010; Gustafson \& Lawson, 2006; Laird et al., 2016; Yao \& Rhodes, 2015) and reviews of reviews (Bauman et al., 2012; Biddle et al., 2011; Sterdt etal., 2011) focused on analysing parents' influence, showed consistently that parents' support was an important correlate of PA for children and adolescents. Support to participate in PA was identified as the most important correlate, followed by encouragement and transportation (Yao \& Rhodes, 2015). Parental support seems to be particularly important for participation in vigorous and organized PA and for total PA in youth (Edwardson \& Gorely, 2010; Laird et al., 2016).

Regarding friends, several reviews report that children and adolescents PA was either not (Lubans, 2008; Sallis et al., 2000) or inconsistently (Craggs et al., 2011; Ferreira et al., 2006) related to their friends' PA, such as in one review of reviews (de Vet et al., 2011). Similar results were found regarding the association between friends' support and children (Craggs et al., 2011) and adolescents (Biddle et al., 2005; Craggs et al., 2011; Ferreira et al., 2006; Sallis et al., 2000) PA. In opposition, Lubans et al. (2008) and Van der Horst et al. (2007) found a positive association between friends' support and adolescents' PA. This review findings are similar to other reviews focused on the influence 
of friends in youth PA, as they support the existence of a favourable association, highlighting as influencemechanism the support given(Laird et al., 2016; Maturo \& Cunningham, 2013), co-participation (Maturo \& Cunningham, 2013) and friends' PA(Laird et al., 20016; Maturo \& Cunningham, 2013; Sawka et al., 2013).

Social support from significant others was a positively associated factor to adolescents'PA(Craggs et al., 2011; Ferreira et al., 2006; Laird et al., 2016; Sallis et al., 2000; Sterdt et al., 2014). However, in the reviews that support this association, the definition of significant others is not consensual. For example, Ferreira et al. (2006) identified significant others as parents, siblings, friends or adults, while Sallis et al. (2000) although using the same expression did not gave a definition.

Environmental correlates of physical activity for children and adolescents

Regarding environmental factors, several reviews and reviews of reviews (Biddle et al., 2011; de Vet et al., 2014; Sterdt et al., 2014) support accessibility, availability and proximity, equipment and PA programs as being positively associated to PA in children (Davison \& Lawson, 2006; Ding et al., 2011; Oliveira et al., 2014; Sallis et al., 2000) and adolescents (Davison \& Lawson, 2006) (table 7). On the other hand, some reviews did not find any association (Ferreira et al., 2006; Van der Horst et al., 2007) or found inconclusive results (Craggs et al., 2011).

\begin{tabular}{|c|c|c|c|c|c|c|c|c|c|c|}
\hline & Sallis & Davison & Ferreira & Van der Horst & Craggs & Ding & Oliveira & Biddle & e de Vet & Sterdt \\
\hline Correlates & 2000 & 2006 & 2006 & 2007 & 2011 & 2011 & 2014 & 2011 & 2011 & 2014 \\
\hline $\begin{array}{l}\text { Equipment, spaces and facilities for physical activity } \\
\text { (availability, accessibility, proximity) }\end{array}$ & $+/ 0$ & + & $0 / 0$ & $0 / 0$ & ?/? & +1 & +1 & $+/+$ & + & $+/+$ \\
\hline Time outdoors & +1 & & +1 & & & & & +1 & & +1 \\
\hline Land-use mix/destinations & & + & & & & t+t & & & & \\
\hline Traffic speed/volume & & - & & & ?/? & -1 & ? & & - & \\
\hline Neighbourhood crime & & - & 1- & & ?/? & & ? & - & & \\
\hline Walking and biking facilities & & & & & & +1 & +1 & & & \\
\hline School-home distance & & - & & & ?/? & & & - & & \\
\hline School physical activity policy & & & +1 & & & & & & 0 & \\
\hline Public school and non vocational school & & & 1+ & & & & & & + & \\
\hline School physical activity facilities & & + & & & & & & & + & \\
\hline
\end{tabular}

Time spent outside seems to be positively associated to PA in children (Biddle et al., 2011; Sterdt et al., 2014), as well as the existence of sidewalks and bike paths seems to be associated to active commuting (Ding et al., 2011; Oliveira et al., 2014). If there is a large distance between home and school, children tend to have lower levels of PA (Davison \& Lawson, 2006; Biddle et al., 2011).

The proximity between destinations in the neighbourhood/ community (Davison \& Lawson, 2006; Ding et al., 2011) was positively associated with higher levels of PA in children and adolescents. Neighbourhood crime and traffic speed/volume tend to be negatively (Biddle et al., 2011; Davison \& Lawson, 2006; Ding et al., 2011; de Vet, et al., 2011; Ferreira et al., 2006) or inconsistently (Craggs et al., 2011; Oliveira et al., 2014) associated to PA.

Concerning school, the main focus of this study, de Vet et al. (2011) identified public schools and school facilities to be positively associated to PA in youth, but not school support. Findings regarding the type of school were according to Ferreira et al. (2006) results. However, findings regarding school support seem to be opposite to Ferreira et al. (2006) results, as they found that PA policies in schools (e.g. time available to non-organized PA, time spent in the outside facilities, number of school trips) to be positively associated to children PA.

Implications for physical education based on a socio-ecological approach

The present narrative review of reviews synthesized the correlates of PA. For children and adolescents, the main correlates of PAwere: sex (male), self-efficacy, previous PA, parental support, availability and access to facilities and programs of PA. In a lesser extent, PA attitude, friends support, school facilities and land-mix use might also be other relevant correlates. For children, time spent outside was consistently associated with greater PA levels. For adolescents, ethnicity («Caucasian»), socioeconomic status, motivation, perception of competence, and sport participation were positively related to PA. The decline of PA appears to be most predominante in adolescence.

$\mathrm{PE}$ teachers might use the identified correlates of PA in different ways to develop effective programs and strategies for promoting physically active lifestyles among children and adolescents. First, the non-modifiable factors (e.g. sex, age) might contribute to design targeting interventions to groups in risk of being inactive (Sallis \& Owen, 2015). Second, the modifiable factors (e.g. self-efficacy) can be used to guide the design of intervention's content. This means that effective interventions should modify the factor (or factors) that control PA (Sallis \& Owen, 2015). Third, in considering the role of PE in promoting active lifestyles, it is clear that a multilevel approach is required (Solmon, 2015). Therefore, we think that a socio-ecological framework for PE might be a useful reference through which to view, understand, teach and promote children and adolescents' PA levels within and beyond the school community and across their lifespan (Martins et al., 2015; McKenzie \& Lounsbery, 2013; O’Connor et al., 2012; Solmon, 2015).

Based on these principles, the implications for $\mathrm{PE}$ are organized as follows: (1) active PE; (2) learning focused PE and PA for life; (3) Motivational climate in PE, students' psychosocial profiles and PA; and (4) Family, friends, PE and PA; and (5) PE and a comprehensive school PA promotion.

\section{Active physical education}

By providing in-class $\mathrm{PA}, \mathrm{PE}$ has the potential to make a significant contribution to the daily accumulation of MVPA (Lonsdale et al., 2013; Slingerland \& Borghouts, 2011). It is recommended that students' should spend at least $50 \%$ of the $\mathrm{PE}$ class time in moderate to vigorous PA (MVPA) (IOM, 2013; UNESCO, 2015), which does not occur in the majority of classes (McKenzie \& Lounsbery, 2013; Slingerland \& Borghouts, 2011). Active PE is important for students' health, physical skills and fitness development (McKenzie \& Lounsbery, 2013). Moreover, this is critical for those identified subgroups at risk of being inactive, such as low socioeconomic status students, adolescents and girls. However, there is evidence that PE interventions can increase students' MVPA during lessons (Lonsdale et al., 2013; McKenzie \& Lounsbery, 2013; Slingerland \& Borghouts, 2011). Most effective strategies were related to changes in the curriculum (e.g. replace less active games for more active ones, modified activities, fitness infusion) and improved teacher management skills (e.g. reduce instruction and organization time; maximize equipment use; establishing routines).

\section{life \\ Learning focused physical education and physical activity for}

In addition to active classes, PE teachers should provide ample and enjoyable learning opportunities for all students to develop their skills, values, confidence and knowledge to be physically active outside of PE classes, and throughout their lifetime (McKenzie \& Lounsbery, 2013; UNESCO, 2015). Quality PE should, therefore, be inclusive and address the needs of all students (UNESCO, 2015). The present narrative review suggests that there are student demographic and behavioural characteristics implications and, therefore, PE teachers may need to develop different strategies to be effective in promoting increased PAin children or adolescents, girls, students from a low socioeconomic status, or who have had limited or negative previous PA experiences. In this regard, an important strategy is to provide challenging activities for all students. The STEP (Space, Task, Equipment, People) model (Wiedemann et al., 2014) might help PE teachers think through the 
modifications needed to make the activity more challenging, inclusive, enjoyable and physically and emotionally safe for each student.

Motivational climate in physical education, students' psychosocial profiles and physical activity

Active classes and PE learning activities should occur in amotivational climate that enhances relevant modifiable correlates of PA, such as, selfefficacy for children and adolescents, and perceived competence, autonomous motivation (intrinsic and self-determined) and a mastery goal orientation for adolescents. Several PE interventions have targeted these socio-cognitive and motivational constructs in order to both involve students' in active classes and provide them the skills, knowledge and motivation for adopting and maintaining an active lifestyle (McKenzie \& Lounsbery, 2013; Slingerland \& Borghouts, 2011). Evidence suggests that interventions targeting the hypothesized mediator of behaviour change are more effective in changing behaviour than atheoretical ones (Lonsdale et al., 2013).

Regarding self-efficacy, considering the socio-cognitive theory (Bandura, 1982) it might be important for PE teachers to plan and implement strategies that reinforce the sources of this construct. For example, a PE teacher can: (1) increase students' experiences of success in specific PE and PA situations; (2) provide positive, specific and realistic feedback; (3) help students deal with their emotions that affect the performance of a specific PE and PA activity (e.g. frustration, fear); and (4) develop students' necessary specific behavioural skills for an active lifestyle, related to establishing goal settings, strategic planning, self-monitoring and self-reflection.

Perception of competence is a more global construct than selfefficacy (Harter, 2003). Providing students with developmental appropriated and challenging PE activities, as well as positive reinforcement, might lead to increases in this construct.

As for the motivation, Achievement Goal Theory (AGT) (Nichols, 1989) and Self-Determination Theory (SDT) (Ryan \& Deci, 2007) have proved to be useful in explaining students' behaviour, cognition and affect in PE and regular PA outside PE (Braithwaite, Spray \& Warburton, 2011; Lonsdale et al., 2013; Van den Berghe, Vansteenkiste, Cardon, Kirk \& Haerens, 2014).

The TARGET (Task, Authority, Recognition, Grouping, Evaluation, Time) framework provides guidance for PE teachers implementing a mastery motivational climate that is related with a mastery achievement goal (i.e. evaluate one's competence by selfimprovement and mastery of skills) and other positive outcomes, such as PA (Braithwaite et al., 2011). To increase intrinsic motivation, PE teachers can adopt strategies that support students' psychological basic needs, such as autonomy, competence and relatedness (Ryan \& Deci, 2007).

Stemming from AGT (Braithwaite et al., 2011) and SDT (Ryan \& Deci, 2007), for developing positive students' motivational profiles favourable to PE and PA regular practice, PE teachers should establish a motivational climate that: (1) emphasizes effort and personal improvement; (2) provides enjoyable, diverse and challenging activities; (3) provides choice and leadership opportunities for students; (4) emphasizes positive evaluation for personal improvement; (5) variability in the pace of leaning is considered; and (6) students work in mixed ability groups, in a safe and cooperative climate. Interventions conducted with PE teachers provide support for the importance of adopting pedagogical strategies based on motivation theories (Braithwaite et al., 2011; Van den Berghe et al., 2014; Aelterman, Vansteenkiste, Van den Berghe, De Meyer \& Haerens, 2014).

\section{Family, friends, physical education and physical activity}

The present narrative review suggests that social support from family (for children and adolescents) and from friends (for adolescents) seems to be associated to PA. We acknowledge that these are not easy «variables» for PE teachers to reach and intervene. However, to promote PA it is important to address to adress or at least acknowledge them.
Parents function as gatekeepers of their child PA opportunities. Because parents' social support for PA, as encouragement and logistic, seems to be important across childhood and adolescence, PE teachers should try to engage them in some school, PA and PE activities. There is evidence that multilevel school PE and PA interventions that involve parents tend to be more effective (McKenzie \& Lounsbery, 2013). For example, $\mathrm{PE}$ teachers can increase parents' knowledge and raise awareness regarding the importance of $\mathrm{PA}$ and $\mathrm{PE}$, and their role in supporting their child to have a physically active lifestyle.

In regards to friends, in PE classes the PE teacher can and should promote cooperation, inclusion, respect for difference and social relationships between students. Accordingly, inclusive or reciprocal teaching styles can be used. By understanding the social relationships of their students, PE teacher can also indirectly intervene by asking more active students to help their friend to be more active, in PE and outside PE. Encouragement, verbal persuasion, co-participation and logistical support (e.g. share transportation) are some of the ways that might influence friends' behaviour change.

\section{Physical education and a comprehensive school physical activity} promotion

The limited frequency and duration of PE classes do not allow providing per se the recommended 60 minutes of MVPA for children and adolescents (WHO, 2010). Actually, it is recommended that schools should provide access to at least 60 minutes per day of MVPA, more than half should be accomplished during school hours (IOM, 2013; UNESCO, 2015). For getting students more active, PE teachers are assumed to take a central role in this "whole of school approach", involving distinct teachers, principals, students, parents, and community agents. For example, it is suggested that at the school level, PE teachers should be the catalyst for: (1) promoting the importance of PE and PA with their principals and other teachers; (2) establishing networks with stakeholders; (3) helping to structure and deliver diverse PAopportunities to increase students' MVPA (IOM, 2013; McKenzie \& Lounsbery, 2013). For intervening at this level, it seems fundamental to have a strong group of $\mathrm{PE}$ teachers.

In their classes, $\mathrm{PE}$ teachers should explicitly recommend students to explore PA opportunities throughout the school days (e.g. recess, active classes, tournaments), before and after school (e.g. extracurricular activities, school sport), as well as within the community (e.g. active commuting, sports clubs, informal PA) (IOM, 2013; McKenzie \& Lounsbery, 2013; UNESCO, 2015). The present review suggests that access to facilities and PA programs in the community were associated to higher PA levels. It might be more difficult for a teacher to intervene at the community level, but there are things that can be done. For example, PE teachers can help their students to identify opportunities to be active in the community and teach them how to overcome barriers (Mckenzie \& Lounsbery, 2013).

\section{Limitations and strengths}

Some limitations of the present study are aligned with those from several reviews and reviews of reviews (e.g. Biddle et al., 2011; Sallis et al., 2000; Sterdt et al., 2014). Several heterogeneous and inconsistent results were found in correlates of PA. These reviews included primary studies that showed lack of consistency in methods of measuring PA (type, context, intensity), were mainly cross-sectional, and adopted different definitions for constructs being measured (e.g. PA, social support). Despite including reviews focused in several subgroups or variables, such as girls (Biddle et al., 2005), age (Dumith et al., 2011) and socioeconomic status (Stalsberg \& Pedersen, 2010), the results in general do not allow to identify the specific correlates for each subgroups. By the other hand, the present narrative review is unique in critically analysing extended evidence stemming from reviews about the correlates of PA and how this could be translated into PE, based on a socioecological approach. 


\section{Conclusion}

The identified correlates in the narrative review of the reviews suggest that teachers should design PE activities and implement strategies that build students' self-efficacy, motivation and perceived competence, stimulate parental and friends' social support. PE classes should be active, inclusive and address the needs of all students. PE teachers need to develop specific strategies for subgroups at risk of being inactive, such as adolescent girls, low socioeconomic status students, and those who did not have previous experiences of PA. Actually, for promoting active and healthy lifestyles, it is clear that PE teachers' role must advance beyond PE, embrace school and community layers. For example, diverse opportunities for MVPA should be provided for all students in PE, school and community contexts. Through employing a socioecological framework for PE, several pedagogical strategies were identified that might be useful in order to increase $\mathrm{PE}$ effectiveness in promoting active lifestyles. Pre-service and in-service education of PE teachers might consider addressing: 1) quality PE; 2) instructional practices for active and quality PE; 3) promoting PA within and beyond school, and throughout life; 4) the socio-ecological model for PE; 5) behavioural theories and the promotion of PA through PE; and 6) develop and implement a PE curriculum based on the main correlates of PA.

\section{Acknowledgements}

This work is part of a major research project distinguished by the Portuguese Olympic Committee with an honourable mention.

\section{References}

Aelterman, N., Vansteenkiste, M., Van den Berghe, L., De Meyer, J., \& Haerens, L. (2014). Fostering a need-supportive teaching style: Intervention effects on physical education teachers' beliefs and teaching behaviors. Journal of Sport \& Exercise Psychology, 36, 595-609.

Bandura,A.(1982). Self-efficacy mechanism in human agency.American Psychologist, 37(2), 122-147.

Bauman, A., Reis, R., Sallis, J., Wells, J., Loos, R., \& Martin, B. (2012). Correlates of physical activity: Why are some people physically active and others not? The Lancet, 380, 258-271.

Biddle, S., Atkin, A., Cavill, N., \& Foster, C. (2011). Correlates of physical activity in youth: a review of quantitative systematic reviews. International Review of Sport and Exercise Psychology, 4(1), 25-49.

Biddle, S., Whitehead, S., O’Donovan, T., \& Nevill, M. (2005). Correlates of participation in physical activity for adolescents girls: A systematic review of recent literature. Journal of Physical Activity and Health, 2, 423-434.

Braithwaite, R., Spray, C., \& Warburton, V.(2011). Motivational climate interventions in physical education: A meta-analysis. Psychology of Sport and Exercise, 12, 628-638.

Castelli, D., Centeio, E., Hwang, J., Barcelona, J., Glowacki, E., Calvert, H., \& Nicksic, H. (2014). VII. The history of physical activity and academic performance research: Informing the future. Monographs of the Society for Research in Child Development, 79(4), 119-148.

Craggs, C., Corder, K., van Sluijs, E., \& Griffin, S. (2011). Determinants of change in physical activity in children and adolescents: A systematic review. American Journal of Preventive Medicine, 40(6), 645-658.

Davison, K., \& Lawson, C. (2006). Do attributes in the physical environment influence children's physical activity? Areview of the literature. International Journal of Behavioral Nutrition and Physical Activity,3(19). doi: 10.1186/1479-5868-3-19

de Vet, E., Ridder, D., \& Wit, J. (2011). Environmental correlates of physical activity and dietary behaviours among young people: a systematic review of reviews. Obesity Prevention, 12, e130-e142.

Devís-Devís, J., Beltrán-Carrillo, V.\& Peiró-Velert, C. (2015). Exploring socio-ecological factors influencing active and inactive Spanish students in years 12 and 13. Sport, Education and Society, 20(3), 361-380.

Ding, D., Sallis, J., Kerr, J., Lee, S., \& Rosenberg, D. (2011). Neighborhood environment and physical activity among youth. A review. American Journal of Preventive Medicine, 41(4), 442-455.

Dumith, S., Gigante, D., Domingues, M., \& Kohl, H. (2011). Physical activity change during adolescence: a systematic review and a pooled analysis. International Journal of Epidemiology(40), 685-698.

Edwardson, C., \& Gorely, T. (2010). Parental influences on different types and intensities of physical activity in youth: A systematic review. Psychology of Sport and Exercise, 11, 522-535.

Ferreira, I., Van der Horst, K., Wendel-Vos, W., Kremers, S., Van Lenthe, F., \& Brug, J. (2006). Environmental correlates of physical activity in youth - a review and update. Obesity Reviews, 8, 129-154.

Grant, M., \& Booth, A. (2009). A typology of reviews: an analysis of 14 review types and associated methodologies. Health Information and Libraries Journal, 26, 91-108.

Gustafson, S., \& Rhodes, R. (2006). Parental correlates of physical activity in children and early adolescents. Sports Medicine, 36(1), 79-97.

Hallal, P., Bo Andersen, L., Bull, F., Guthold, R., Haskell, W., \& Ekelund, U. (2012). Global physical activity levels: surveillance progress, pitfalls, and prospects. The Lancet, 280, 247-257.

Hanson, M., \& Chen, E. (2007). Socioeconomic status and health behaviors in adolescence: A review of the literature. Journal of Behavioural Medicine, 30, 263-285.

Harter, S. (2003). The development of self-representations during childhood and adolescence. In R. Leary \& J. Tangney (Eds.), Handbook of self and identity. (pp. 610-642). New York, NY: Guilford Press.

Institute of Medicine. (2013). Educating the student body: Taking physical activity and physical education to school. Washington, DC.

Laird, Y., Fawkner, S., Kelly, P., McNamee, L., \& Niven, A. (2016). The role of social support on physical activity behaviour in adolescent girls: a systematic review and meta-analysis. International Journal of Behavioral Nutrition and Physical Activity, 13(79).

Lim, C., \& Biddle, S. (2012). Longitudinal and prospective studies of parental correlates of physical activity in young people: A systematic review. International Journal of Sport and Exercise Psychology, 10(3), 211-220.

Lonsdale, C., Rosenkranz, R., Peralta, L., Bennie, A., Fahey, P., \& Lubans, D. (2013). A systematic review and meta-analysis of interventions designed to increase moderate-to vigorous physical activity in school physical education lessons. Preventive Medicine, $56,152-161$.

Lubans, D., Foster, C., Biddle S (2008). A review of mediators of behavior in interventions to promote physical activity among children and adolescents. Preventive Medicine, 47, 463-70.

Martins, J., Marques, A., Rodrigues, A., Sarmento, H., Onofre, M., \& Carreiro da Costa, F. (2016). Exploring the perspectives of physically active and inactive adolescents: How does physical education influence their lifestyles? Sport, Education \& Society. doi: 10.1080/13573322.2016.1229290

Maturo, C., \& Cunningham, S. (2013). Influence of friends on children's physical activity: A review. American Journal of Public Health, 103(7), e23-e38.

McKenzie, T., \& Lounsbery, M. (2013). Physical education teacher effectiveness in a public health context. Research Quarterly for Exercise and Sport, 84, 419-430.

Nicholls, J. (1989). The competitive ethos and democratic education. Cambridge, MA: Harvard University Press.

Oliveira, A., Moreira, C., Abreu, S., Mota, J., \& Santos, R. (2014). Environmental determinants of physical activity in children: A systematic review. Archives of Exercise in Health and Disease, 4(2), 254-261. 
O’Connor, J., Alfrey, L., \& Payne, P. (2012). Beyond games and sports: A socio-ecological approach to physical education. Sport, Education and Society, 17(3), 365-380.

Ryan, R., \& Deci, E. (2007). Active human nature: Self-determination theory and the promotion and maintenance of sport, exercise and health. In M. Hagger \& N. Chatzisarantis(Eds.), Intrinsic motivation and self-determination in exercise and sport (pp. 1-19). Champaign, IL: Human Kinetics.

Sallis, J., Bull, F., Guthold, R., Heath, G, Inoue, S., Kelly, P., Oyeyemi, A., Perez, L., Richards, J., Hallal, P. (2016). Progress in physical activity over the Olympic quadrennium. The Lancet, http:// dx.doi.org/10.1016/S0140-6736(16)30581-5.

Sallis, J., Prochaska, J., \& Taylor, W. (2000). A review of correlates of physical activity of children and adolescents. Medicine \& Science in Sports \& Exercise, 32(5), 963-975.

Sallis, J., \& Owen, N. (2015). Ecological models of health behavior. In K. Glanz, B. Rimer, \& K. Viswanath (Eds.), Health behavior. Theory, Research and Practice (5 ed.). San Francisco, CA: JosseyBass.

Sawka, K., McCormack, G., Nettel-Aguirre, A., Hawe, P., \& DoyleBaker, P. (2013). Friendship networks and physical activity and sedentary behavior among youth: a systematized review. 10, 130139.

Stalsberg, R., \& Pedersen, A. (2010). Effects of socioeconomic status on the physical activity in adolescents: a systematic review of the evidence. Scandinavian Journal of Medicine \& Science in Sports, 20, 368-383.

Slingerland, M., \& Borghouts, L. (2011). Direct and indirect influence of physical education-based interventions on physical activity: A review. Journal of Physical Activity and Health, 8, 866-878.

Solmon, M. (2015). Optimizing the role of physical education in promoting physical activity: Asocial-ecological approach. Research Quarterly for Exercise and Sport, 86(4), 329-337.
Sterdt, E., Liersch, S., \& Walter, U. (2014). Correlates of physical activity of children and adolescents: Asystematic review of reviews. Health Education Journal, 73(1), 72-89.

Telama, R., Yang, X., Leskinen, E., Kankaanpa, A., Hirvensalo, M., Tammelin, T., ... Raitakiri, O. (2014). Tracking of physical activity from early childhood through youth into adulthood. Medicine \& Science in Sports \& Exercise, 46(5), 955-962.

Uijtdewilligen, L., Nauta, J., Singh, A., van Mechelen, W., Twisk, J., van der Horst, K., \& Chinapaw, C. (2011). Determinants of physical activity and sedentary behaviour in young people: a review and quality synthesis of prospective studies. British Journal of Sports Medicine, 45, 896-905.

United Nations Educational Scientific and Cultural Organization. (2015). Quality physical education: Guidelines for policy- makers. Paris: Author.

Van den Berghe, L., Vansteenkiste, M., Cardon, G., Kirk, D., \& Haerens, L. (2014). Research on self-determination in physical education: Key findings and proposals for future research. Physical Education and Sport Pedagogy, 19(1), 97-121.

Van der Horst, K., Chin, M., Twisk, J., \& Van Mechelen, W. (2007). A brief review on correlates of physical activity and sedentariness in youth. Medicine \& Science in Sports \& Exercise, 39(8), 12411250.

Wiedemann, N., Ammann, M., Bird, M., Engelhardt, J., Koenen, K., Meier, M., Schwarz, D. (2014). Moving together. Promoting psychosocial well-being through sport and physical activity. Denmark: PS Centre.

World Health Organization. (2010). Global recommendations on physical activity for health. Geneva: Author.

Yao, C., \& Rhodes, R. (2015). Parental correlates in child and adolescent physical activity: a meta-analysis. International Journal of Behavioral Nutrition and Physical Activity, 12(10).

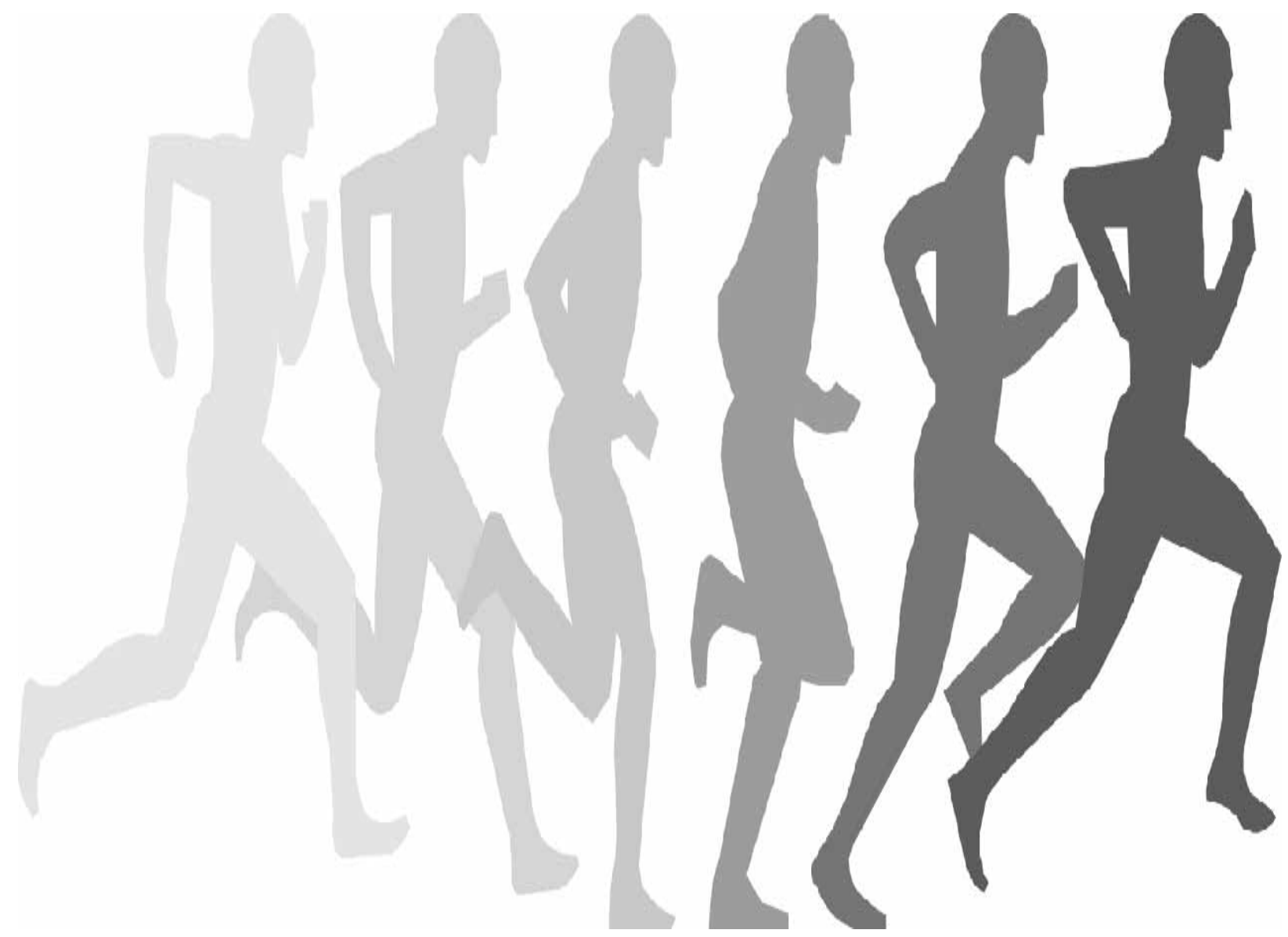

